\title{
A síncope no latim vulgar e no português
}

DOI: http://dx.doi.org/10.21165/el.v50i3.3017

\section{Antonio Carlos Silva de Carvalho' Marcelo Módolo²}

\section{Resumo}

Tendo em vista a metáfora utilizada por Serafım da Silva Neto em sua História do latim vulgar segundo a qual a língua falada seria um rio e a língua escrita culta a justaposição de camadas de gelo em sua superfície, exploramos certos fatos linguísticos relativos aos metaplasmos (sob a perspectiva da gramática histórica) que, correntes no latim, continuam seguindo seu curso no português. Procuramos restringir o estudo a um metaplasmo de subtração de amplo alcance, a síncope, considerando-o à luz da "lei do menor esforço". Assim, focamos manifestações desse fenômeno no latim vulgar e no português atual para discutir sua produtividade e conceptualização. Quanto ao corpus, utilizamos o Appendix Probi e palavras extraídas de contextos não-formais, figurantes nas redes sociais, além de termos oriundos de material jornalístico e literário.

Palavras-chave: metaplasmos; síncope; divergentes; lei do menor esforço; linguística histórica.

1 Sem vínculo institucional; carloscarval67@gmail.com; https://orcid.org/0000-0002-0353-0918

2 Universidade de São Paulo (USP), São Paulo, São Paulo, Brasil; modolo@usp.br; https://orcid.org/0000-0001-5808-9368 


\title{
Syncope in Vulgar Latin and Portuguese
}

\begin{abstract}
Given the metaphor used by Serafim da Silva Neto in his História do latim vulgar, which states that spoken language would be a river whereas standard written language would be the juxtaposition of ice sheets on its surface, we explore specific linguistic facts concerning metaplasms (from the historical grammar perspective) which, current in Latin, continue to follow their course in Portuguese. We have tried to narrow the study down to a wide-ranging metaplasm of subtraction, syncope, considering it in the light of the "law of the least effort". Thus, we focus on manifestations of this phenomenon in Vulgar Latin and current Portuguese to discuss their productivity and conceptualization. As for the corpus, we have used the Appendix Probi and the words extracted from nonformal contexts featured on social networks, in addition to terms derived from journalistic material.
\end{abstract}

Keywords: metaplasms; syncope; doublets; law of least effort; historical linguistics.

\section{Introdução}

A bela metáfora empregada pelo filólogo e linguista brasileiro Serafim da Silva Neto em sua História do latim vulgar descreve a língua falada como um rio e a língua escrita culta, burilada por escritores e registrada pelos gramáticos, como a justaposição de camadas de gelo em sua superfície. Vislumbrando essa metáfora, exploramos aqui certos fatos linguísticos referentes aos metaplasmos (considerados sob a perspectiva da gramática histórica) que, correntes no latim, continuam seguindo seu curso também no português, como água que, ao sulcar as camadas do gelo, ajuda a moldar, particularizando, a paisagem. Este trabalho é uma versão modificada e muito ampliada de Carvalho e Módolo (2020).

Devido a sua abrangência, as possibilidades de abordagem do tema são inúmeras, razão por que procuramos, tanto quanto possível, restringir este estudo a um metaplasmo de subtração de amplo alcance, a síncope, sempre tendo como pano de fundo a "lei do menor esforço", também conhecida como princípio da economia ou, mesmo, como "lei da preguiça", muito comum na coloquialidade da linguagem falada, que naturalmente segue regramento distinto do característico da língua escrita culta.

Vez que o ponto inicial das línguas românicas é o latim vulgar, utilizamos para o estudo dessa modalidade latina o Appendix Probi, valiosa fonte composta por uma relação de pares de palavras constantes no livro Instituta Artium, de Valerius Probus (I d.C.); dessa relação, destacamos alguns pares para averiguação da síncope, fenômeno linguístico bastante atuante no processo do estabelecimento do português como língua paroxítona. 
Feitas essas considerações, direcionamos a pesquisa para o português atual, incluindo então a haplologia e explorando um corpus variado constituído de palavras extraídas de contextos não-formais, figurantes nas redes sociais, além de termos oriundos de material jornalístico e, mesmo, literário ${ }^{3}$. Nesse percurso, observamos que as tendências permanecem, embora com algumas diferenças.

\section{Só uma mudança da paisagem}

Na literatura técnica, nem sempre os autores apresentam as mesmas definições, e com o termo metaplasmos não se dá algo diferente, conforme atestam estas duas definições que destacamos: i) "Mudança da forma de uma palavra..." (JOTA, 1976, p. 205); e ii) "são modificações fonéticas que sofrem as palavras na sua evolução" (COUTINHO, 1974, p. 142). Assim, cremos que ambas as definições não apenas não são excludentes como também se complementam, na medida em que as transformações sofridas pelas palavras sujeitas à ação dos metaplasmos se dão por motivação fonética.

Evidentemente, as mudanças fonéticas e morfológicas nas palavras ocorrem segundo as tendências de cada geração e só se cristalizam após a passagem de muito tempo, quando enfim o cotejo entre um estágio e outro da língua permite destacar semelhanças e diferenças por trás da nova roupagem da palavra, como "leer", português arcaico, e "ler", português moderno. Todavia, em meio a outras, uma lei tida pelos velhos gramáticos como "lei do menor esforço" e cuja atuação sobre os metaplasmos é inegável costuma sempre permear essas transformações; segundo ela, por razões como não monitoramento, tendemos a economizar esforço no ato da fala - é o que ocorre quando coloquialmente usamos "magina" (por "imagina", ${ }^{4}$ subtraindo o "i" inicial) ou "pire" (por "pires", eliminando o "s" final).

$\mathrm{Na}$ tradição greco-latina, os metaplasmos indicavam as formas diversas - uma variante em face de uma forma básica - dos vocábulos em um dado estado da língua (CÂMARA JR., 1974), como o que podemos flagrar hodiernamente nos pares "bicicleta" por "bicicreta", "voar" por "avoar", "abóbora" por "bobra" e "vidro" por "vrido". De natureza

3 A exemplificação avulsa foi praticamente toda extraída da internet, cuja pluralidade obrigou-nos a consultar várias páginas. Não julgamos conveniente citá-las uma a uma detalhadamente, haja vista serem facilmente encontráveis com o buscador Google a partir dos dados que fornecemos. Também, a poluição visual seria, a nosso entender, desnecessária e maior que o rigor científico para as dimensões desse trabalho.

4 Vale observar que Vieira (1873, v. 4, p. 25) atesta o verbete "Maginar" como variação de "Imaginar", em que teria ocorrido, portanto, um metaplasmo denominado aférese "processo de mudança linguística que consiste na supressão de fonema(s) no princípio de vocábulo [...]" (HOUAISS, 2009, p. 60).

5 A palavra "por" entre duas formas em variação remete sempre ao sentido de "realizado como/ no lugar de". 
sincrônica, estática, isto é, levando em conta os fatos da língua num dado momento de sua história, esse conceito cedeu lugar a um de natureza diacrônica, essencialmente dinâmico, que aborda as transformações da língua em sua evolução, de geração para geração - no tocante ao português, do latim vulgar aos dias atuais -, considerando aspectos fonéticos de permuta, aumento, subtração ou transposição de partes da palavra.

Pensando exclusivamente no português, os metaplasmos permitem, por exemplo, discernir se os vocábulos são: i) populares, vernáculos ou herdados, isto é, os que constituem o léxico fundamental da língua - tendo sofrido as mudanças fonéticas regulares do português, ou seja, a ação de certas leis de natureza sonora próprias de uma determinada época ou, mesmo, constantes da língua, como a tendência à sonorização -, apresentando-se muito modificados em face do vocábulo original; ii) semieruditos, aqueles vocábulos introduzidos na língua portuguesa em um tempo posterior por intermédio de meios sociais versados na língua do Lácio - os quais não se submeteram à ação do mesmo conjunto de mudanças fonéticas que incidiu sobre o grupo anterior, como a supressão da vogal postônica, sofrendo menos e diferentes alterações a depender da camada social com a qual está em contato; e iii) eruditos, vocábulos cuja introdução no português foi tardia e se deu por pessoas com bom conhecimento de latim - não revelam mudanças fonéticas em face da forma original, salvo uma ou outra adaptação ao sistema atual da língua. Não raro, dependendo da incidência das mudanças fonéticas a que são submetidos, vocábulos eruditos e vocábulos populares de uma origem em comum - os cognatos e principalmente os divergentes, também chamados alótropos ou alotrópicos - desenvolvem radicais de tal modo diversos (por razões de natureza geográfica, cronológica ou social), que só a gramática histórica possibilita o estabelecimento de seu parentesco (ELIA, 1962).

Sobre essas palavras divergentes ou alotrópicas - assim chamadas em alusão aos empréstimos ou contatos culturais no português entre vocábulos diferentes, mas de um mesmo étimo, sendo ao menos um deles de outra língua românica, segundo Câmara Jr. (1974), ou do latim e do grego, segundo Elia (1962) -, cujas diferenças, conforme vimos, ocorrem também pela ação dos metaplasmos, é conveniente atentarmos a estas ainda muito pertinentes considerações de Vieira:

Muitas palavras latinas appresentam-se em portuguez sob dous ou mais aspectos phonicos differentes. Esses aspectos phonicos são conhecidos pelo nome de duplos ou pelo melhor de fórmas divergentes ${ }^{1}$.

As fórmas divergentes teem diversas causas que passamos a examinar.

1. No periodo de formação da lingua, isto é, n'aquelle periodo em que o latim adquiriu os caracteres que reconhecemos no portuguez no momento em que apparece escripto, muitas palavras adquiriram uma ou mais significações novas conservando ou perdendo as que tinham em latim ora para reflectir no som a differença das significações essas palavras foram tractadas phonicamente em 
dous (ou mais) sentidos diversos: um conforme ás tendencias predominantes da lingua, outro mais ou menos excepcional.

Palavras mesmo que em latim tinham já duas significações diversas foram submetidas a um semelhante processo. [...]. (VIEIRA, 1871, v. 1, p. XXXIX).

O autor destaca a questão das mudanças sonoras ao lado de outras causas que levam a formas divergentes - a denominação "duplos" não se conservou em nossa tradição gramatical $^{6}$ - de palavras com o mesmo étimo. Vale observar que Vieira menciona formas que seguem "tendências predominantes da língua" ao lado daquelas que seguem outras (tendências) mais ou menos excepcionais, isto é, apesar da regularidade, há fatores que podem levar a evoluções diferentes. Na sequência do texto, a explicação é estendida a partir do vocábulo latino macula, que, submetido à ação dos metaplasmos, passa a "malha" quando desejamos expressar "abertura de rede"; quando a ideia é expressar labe [mesmo que labéo, ou labéu, mancha, desonra, nota infame, desdouro], pecado ou sentimento do ânimo, mudamos em "mágoa"; quando queremos significar nódoa, mudamos em "mancha". Enfım, macŭla, frequentemente citado na literatura especializada - como Bassetto, Câmara Jr., Coutinho, Elia, Jota - em função de sua produtividade e relevância para o tema, nos levou à elaboração do quadro que se segue, com o fito de uma visualização mais elucidativa:

Quadro 1. Palavra latina macŭla

\begin{tabular}{|l|l|}
\hline Macŭla & $\begin{array}{l}\text { i) } \text { macŭlam }>\text { macŭla }>\text { macla }\left\{\begin{array}{l}>\text { malha } \\
>\text { mãcla }>* \text { mancla }\end{array}\left\{\begin{array}{l}>\text { mangla }>\text { mangra } \\
>\text { mancha }\end{array}\right.\right. \\
\text { ii) macŭla }>\text { magola }>\text { mágoa } \\
\text { iii) macŭla }>\text { mácula }\end{array}$ \\
\hline
\end{tabular}

Fonte: Elaboração própria

Primeiramente, é necessário explicar esse $m$ acoplado à palavra macŭla, que nada mais é do que a marca do acusativo (singular), vez que é esse o caso lexicogênico do português, ou em outros termos, o acusativo é o caso latino por meio do qual se originou a maior parte do léxico da língua portuguesa. Assim, no item i) temos como resultado palavras vernáculas ou populares, submetidas à síncope da vogal postônica, bastante modificadas em relação ao vocábulo de origem, "malha" e "mancha". Quanto à "mancla", em comunicação pessoal em um curso de Filologia Românica, o professor Bruno Bassetto afirmou ser o nome de uma doença que acomete os cascos dos cavalos, ocasionando

6 Vasconcelos (19-?, p. 35) atesta que os franceses usaram a forma doublets, enquanto os italianos usaram alotropi, no que foram seguidos por Leite de Vasconcelos e Gonçalves Viana em Portugal com alótropos. 
"manchas" brancas, infelizmente porém, não indicou a fonte, todavia, Houaiss indica o seguinte termo que teria se originado do hipotético mancla no latim vulgar:

mangra s. f. (s. XV) 1 FITOP doença que ataca esp. as gramíneas, causada por excesso de umidade do ar ou pelo orvalho que favorece a proliferação de fungos e impede o desenvolvimento de espigas e frutos 2 p.ext. umidade ou orvalho que prejudica os frutos [...] ETIM esp. mangla 'id.', do lat. vulg. *mancla < macŭla, ae 'mancha, malha' [...]. (HOUAISS, 2009, p. 1233).

Novamente, estamos diante de palavra popular, paroxítona, que sofreu síncope da vogal postônica, e que provém do mesmo étimo latino; no item ii) temos como resultado uma palavra semierudita, "mágoa", paroxítona que conserva a vogal postônica, mas sofre outros metaplasmos7; já no item iii) o resultado é "mácula", proparoxítona praticamente idêntica a sua correspondente latina. Evidentemente, nos itens ii) e iii) não se espera a marca de acusativo, pois o conhecedor do latim recorreria diretamente ao léxico da língua.

No mais, naturalmente, um sentido comum pode ser divisado sem maiores dificuldades, como o de "mancha" - datada do século XIV, dentre outras acepções: "3. pequeno espaço de cor diferente em um conjunto de cor uniforme [...]; mesmo que 'malha', 'sinal natural' [...]" (HOUAISS, 2009, p. 1228) - que perpassa todos os vocábulos, por exemplo: a "malha" que indica a "abertura de rede" apresenta o aspecto de "mancha"; uma vaca "malhada" é uma vaca de coloração diversa em diferentes partes do corpo, logo, "manchada"; o termo "malha" referindo-se a um trecho de terreno indica uma porção estreita de solo com coloração diferente, portanto, um terreno "manchado"; a "mangra", doença que ataca as gramíneas, seja pelo orvalho seja pelo excesso de fungos, deixa as gramíneas ou os frutos com pintas similares a "manchas"; uma "mágoa" é uma "mancha" no humor; uma "mácula" é uma "mancha" de caráter moral, uma nódoa sobre a reputação de alguém. Ainda, convém pontuar que "malha" e "mancha" são exemplos de empréstimos culturais entre o português e o francês, conforme o que se segue:

'malha s. f. (s. XIII) 1 TÊXT cada um dos anéis, nós, voltas, laçadas de um fio têxtil que se entrelaçam para formar um tecido flexível e elástico <as $m$. do tricô> 2 p. met. TÊXT esse tecido <suéter de m.> $\mathbf{3}$ cada um dos espaços vazios entre as malhas (acp. 1) [...] ETIM fr. maille 'laçada, anel, mancha' [...]. (HOUAISS, 2009, p. 1223).

7 A propósito, nos exemplos que trazemos, eventualmente metaplasmos de tipos diversos concorreram para as mudanças das palavras, mas nosso foco recai sempre sobre a síncope, metaplasmo de subtração destacado no início, suficiente para as discussões que propomos. 
Esse parentesco assinalado, que nos proporciona a imagem de uma teia - sobretudo na acepção $\mathbf{3}$ acima -, permite afirmar que "malha" e "mancha" são divergentes: a) por viés semântico, graças ao empréstimo francês; b) por viés fonético, devido a procederem de zonas dialetais distintas (logo, por razões concernentes à geografia linguística), caracterizam-se por serem formas populares que sofreram síncope da vogal postônica em um mesmo espaço temporal. Também, vale observar que a influência francesa se deu a partir do século XIII, logo, não influenciou na forma portuguesa de "malha", apenas no uso - dizendo de outro modo, o termo "malha" foi utilizado no período em questão significando coisas distintas por caminhos diferentes. Por outro lado, na comparação com "mácula", registrada no português em 1589 (HOUAISS, 2009, p. 1212), século XVI portanto, observamos outro percurso que aponta no sentido da divergência: c) por viés fonético, que ocorre por questão cronológica e se caracteriza por ser um empréstimo cultural junto ao latim; assim, temos "malha" e "mancha", duas palavras populares, e "mácula", uma palavra erudita ou culta. Algo semelhante pode ser dito a partir do cotejo entre, por exemplo, "mancha" e "mangra", vez que esta figura como um empréstimo cultural junto ao espanhol, outra língua românica. Quanto à "mágoa", vejamos este verbete:

MÁGOA - Do lat. macula, mancha, metaforicamente empregado em sentido moral [...]. Em it. macola. "O primitivo sentido físico encontra-se neste exemplo, colhido em documento do século XV: aquela (ovelha) que era sem magoa. Heitor Pinto diz igualmente: o rosto denegrido e cheio de mágoas. A mesma mudança deu-se, entre outras palavras, em dissabor [...]. (NASCENTES, 1932, p. 482).

Além do étimo latino macula, Nascentes atesta a ocorrência do verbete em outra língua românica (o italiano), menciona os vieses metafórico (moral, relativo à dor) e concreto, físico (relativo à "mancha"), e informa seu registro no português (século XV). No cotejo com "mancha" e "mácula", por exemplo, o tipo de erosão que "mágoa" apresenta indica um estágio intermediário, isto é, trata-se de uma palavra semierudita ou semiculta, devido à manutenção de vogal postônica ao mesmo tempo em que revela síncope da consoante sonora intervocálica. No tocante ao fenômeno da divergência, esse se dá por "causa social", que ocorre quando uma mesma palavra é utilizada por camadas culturalmente diversas da população, resistindo a certas tendências fonéticas e cedendo a outras.

\section{0 rio continua a correr: a lei do menor esforço}

O Appendix Probi, constituído de 227 pares de palavras (incluindo algumas poucas frases) que trazem o registro culto ao lado do vulgar apontando o modo correto da pronúncia, algo do tipo "assim, não assim", comprova a atuação da síncope no período, por exemplo, nos pares: (3) speculum non speclum "espelho", queda do $u^{8}$; (4) masculus non masclus "masculino", queda do $u_{;}(7)$ vernaculus non vernaclus "vernáculo", queda do $u_{;}$(29) avus

8 A numeração indica a posição do par no Appendix Probi. 
non aus "avô", queda do v; (53) calida non calda "cálida", queda do i; (73) favilla non failla "cinza", queda do vi (111) oculus non oclus "olho", queda do $u_{i}$ (200) tribula non tribla "estrepe", queda do u; (201) viridis non virdis "verde", queda do i etc. (DIAZ Y DIAZ, 1950), todos exemplos de síncope da postônica, fenômeno que indica supressão de fonema consonântico ou vocálico e que atuou sistematicamente na evolução do português, a tal ponto que a passagem dos proparoxítonos latinos a paroxítonos no romanço lusitano se deu por sua atuação - algo assaz relevante, tendo em vista o fato de o português ser uma língua paroxítona. No limite, o fenômeno da síncope da postônica remete à noção de economia linguística, muitas vezes chamada de lei da economia fonética, bastante comum no latim vulgar, devido ao caráter não monitorado, característico da língua falada informal (BASSETTO, 2010); todavia, o próprio Bassetto, Camara Jr. e outros preferem a denominação "tendências fonéticas", exatamente por entenderem que as transformações das palavras "variam com a região, o tempo e o ambiente social" (JOTA, 1976, p. 186), causas que, somadas a fatores como a analogia, ajudam a explicar as formas divergentes ou o fato de certas palavras não passarem pelas mesmas modificações do que outras.

Outra síncope que contribuiu para a redução (do número de sílaba) dos vocábulos, sobretudo após a ação de outros metaplasmos, foi a síncope da consoante sonora intervocálica - sonoras são as consoantes que se articulam com vibração das cordas vocais, como $d$, $b$ etc., em oposição às surdas, em cuja emissão não vibram as cordas vocais, como $t, p-$, como a que se observa em colore > coor > cor, em que ocorre a supressão da consoante sonora $I$, e em pede > pee > pé, em que ocorre a queda da consoante sonora d (JOTA, 1976, p. 306). Aqui, convém recorrermos ao Appendix Probi, para algumas considerações sobre o assunto.

O par (130) tabula non tabla "tábua" registra a comentada tendência, comum no latim vulgar, de sincopar a vogal postônica, portanto, esse registro deixa claro que tabula, por via natural, ou seja, submetendo-se às mudanças fonéticas regulares da língua portuguesa, de maneira alguma resultaria "tábua"; com efeito, diacronicamente, o resultado teria que ser, no mínimo, a popular "tabla"; por outro lado, devido à manutenção da vogal postônica u e à síncope da consoante sonora I, temos a semierudita ou semiculta "tábua"9. Ainda, podemos acrescentar dois proparoxítonos interessantes a essa lista, a erudita portuguesa "tábula" e a semierudita portuguesa "távola", que veio por empréstimo do italiano no século XIV e que tem o status de vocábulo panromânico, conforme Houaiss (2009, p. 1819).

Ainda, no português moderno, conforme Jota (1976, p. 306), "observa-se a síncope em certas consoantes desprotegidas como em exceção (de excepção), fato (por facto)" e Câmara Jr. (1974, p. 352) "houve ainda a síncope da oclusiva ou constritiva labial,

9 Em outros termos, estamos diante de processo similar ao que ocorreu com macula e "mágoa", isto é, a transformação de um vocábulo esdrúxulo no latim, tabula, em um grave no português, "tábua". 
como primeiro membro de grupo consonântico, em vocábulos eruditos; ex:: excepção > exceção, aritmética > arimética, etc."; novamente, convém recorrermos ao Appendix Probi. Os pares (154) auctor non autor "autor" e (155) auctoritas non autoritas "autoridade", em que se verifica a queda do $c$, uma oclusiva surda, mostram que, embora mais comum no português moderno, a síncope de consoante desprotegida já ocorria no latim vulgar.

Ainda uma busca no Corpus do Português nos possibilitou cotejo entre alguns pares de palavras com essas características nos séculos XIX, XX e XXI, conforme se segue:

Tabela 1. Ocorrências de palavras com e sem consoante desprotegida

\begin{tabular}{|c|c|c|c|c|c|c|c|c|}
\hline Par & Não Sincopada & Sincopada & Séc. XIX & $\%$ & Séc. XX & $\%$ & Séc. XXI & $\%$ \\
\hline \multirow{2}{*}{1} & actor & & 7 & 7,30 & 641 & 55,90 & 5.949 & 4,10 \\
\hline & & ator & 89 & 92,70 & 506 & 44,10 & 139.051 & 95,90 \\
\hline \multirow{2}{*}{2} & aritmética & & 38 & 100 & 102 & 100 & 1.187 & 99,75 \\
\hline & & arimética & 0 & 0 & 0 & 0 & 3 & 0,25 \\
\hline \multirow{2}{*}{3} & contracto & & 3 & 0,20 & 1 & 0,65 & 211 & 0,10 \\
\hline & & contrato & 1.599 & 99,80 & 153 & 99,35 & 231.122 & 99,90 \\
\hline \multirow{2}{*}{4} & corrupto(a) & & 47 & 88,70 & 79 & 100 & 8.515 & 99,80 \\
\hline & & corruto(a) & 6 & 11,30 & 0 & 0 & 16 & 0,20 \\
\hline \multirow{2}{*}{5} & excepção & & 70 & 22,70 & 453 & 51,40 & 8.493 & 16,80 \\
\hline & & exceção & 238 & 77,30 & 429 & 48,60 & 42.110 & 83,20 \\
\hline \multirow{2}{*}{6} & facto & & 329 & 18,20 & 3.580 & 49,20 & 135.471 & 36,20 \\
\hline & & fato & 1.479 & 81,80 & 3.702 & 50,80 & 239.097 & 63,80 \\
\hline \multirow{2}{*}{7} & secção & & 57 & 48,30 & 326 & 22,70 & 14.171 & 40,30 \\
\hline & & seção & 61 & 52,70 & 1.111 & 77,30 & 20.974 & 59,70 \\
\hline
\end{tabular}

Fonte: Elaboração própria

A opção por esses três séculos se deu em função de abrangerem o português moderno, referido pela literatura linguística da área. Mesmo que os dados tenham vindo de dois subcorpora distintos [séculos XIX e XX pertencem ao subcorpora Género/Histórico ${ }^{10} \mathrm{com}$ 45 milhões de palavras; século XXI pertence ao subcorpora 0 Corpus do Português NOW

10 Esse corpus contém cerca de 45 milhões de palavras de quase 57.000 textos em português entre os anos de 1300 a 1900. As 20 milhões de palavras no texto correspondentes a 1900 são uma mistura entre os gêneros de conversação, ficção, jornais e academia. 
(Notícias na Web) ${ }^{11}$ com aproximadamente 1,4 milhões de palavras], as frequências e porcentagens nos dão pistas sobre o comportamento desse fenômeno no português. Isso posto, no que concerne aos quatro primeiros pares da Tabela 1 acima, observamos que, quanto ao par corrupto(a)/corruto(a), destacamos três ocorrências literárias do século XIX que, na comparação com o século XX e, principalmente, com o XXI, revelam uma singularidade; vejamos:

[...] 0 cheiro da carne corruta porém foi um indício, um raio de luz para o índio que, havendo tomado a peito descobrir a verdade, estava no propósito de não hesitar, para o conseguir, diante da perda da própria vida. (TÁVORA, 1973, p. 101)

O lodo tinha já desaparecido da superfície do charco imundo que ele trazia no coração; restava, porém, ainda no fundo, como se vê, a vasa corruta e pestilencial. (TÁVORA, 1973, p. 110)

[...] É interêsse dos nossos adversários ver-nos afrouxar, a trôco da animação dada à parte corruta do partido. [...]. (ASSIS, 1957, p. 230).

Nas duas primeiras ocorrências, extraídas do romance 0 Cabeleira, lançado pelo escritor cearense Franklin Távora em 1876, e na última, tirada do romance de Machado de Assis, Quincas Borba, lançado em 1891, contemporâneos portanto, encontramos o vocábulo "corruta", a forma já sincopada de "corrupta(o)", o que se faz notável, vez que o cotejo com os séculos seguintes demonstra o apagamento progressivo e total da forma sincopada, que pela lógica deveria ser a evolução do par. Situação idêntica ocorre no par aritmética/ arimética - agravado pelo fato de neste caso a consoante em questão ser da sílaba pretônica, diferentemente daquele, que é da postônica -, logo, constatamos que, no tocante à consoante desprotegida, algo no espírito do povo rejeita a generalização da síncope, sinalizando que a lei da economia fonética enfrenta certas limitações, pois nem sempre o caminho mais curto é o melhor.

Uma dessas limitações, conquanto não seja o caso de nenhum dos pares arrolados, é o problema da homonímia, que tende a ser evitada; de fato, em pares como o substantivo "cacto", planta, e "cato", do verbo catar; o substantivo "pacto" e o substantivo "pato", ave, por exemplo, a consoante desprotegida tende a não sofrer síncope para evitar possível confusão do falante. Nesse sentido, podemos afirmar que a lei do menor esforço se aplica justamente pela manutenção da dificuldade - no caso, a conservação do c, pois que a síncope criaria uma dificuldade maior para o falante. Por outro lado, pensando no vocábulo "ator", é compreensível a síncope da consoante c contrariamente ao que ocorre com sua cognata ou congênere "actante", em função da pouca exposição desta em face daquela nos meios de comunicação. Também, um aspecto a ser considerado quanto à lei

11 O Corpus do Português NOW (Notícias na Web) contém aproximadamente 1.4 milhão de palavras de jornais e revistas on-line desde 2012 até 2019. 
do menor esforço é a inserção de vogal formando sílaba com a consoante desprotegida, por exemplo, em "adapitar" por "adaptar", metaplasmo de adição denominado epêntese (JOTA, 1976) que decorre de acomodação articulatória; como vemos, nem sempre menos é mais. Já quanto aos três últimos pares (excepção/exceção, facto/fato, secção/seção), observamos a tendência natural de incorporar o uso da forma sincopada, seguindo a lógica comum da lei do menor esforço.

Outro fenômeno na passagem do latim para o português que passa pela lei do menor esforço é a síncope de vogal pretônica ou protônica, basicamente limitada a vocábulos polissílabos como delicatu > delgado, veritate > verdade, resecare > rasgar, civitate > cidade, não tendo sido "um fenômeno geral no lat. vulg. e comumente não o é nas línguas românicas; os casos são esporádicos, dependendo de condições regionais" (BASSETTO, 2010, p. 50).

\section{Tendências antigas elucidando o presente}

Devido à natureza dinâmica e ao caráter cíclico da língua, processos verificados no passado remoto ainda ocorrem hoje, como a síncope da vogal postônica que identificamos nos pares "arvre" por "árvore", "chacra" por "chácara", "xicra" por "xícara" e, com o advento da COVID-19, a comuníssima "mascra" por "máscara", frutos da despreocupação própria da linguagem falada, de elocução mais rápida e descuidada que, enquanto conserva o núcleo semântico da palavra, tende a agir sobre a extensão do vocábulo, transformando os proparoxítonos em paroxítonos como nesses pares, o que comprova que a lei do menor esforço continua a ser um norte seguro para o povo, embora não seja o único. É importante essa referência ao núcleo semântico dos vocábulos porque, conforme "verificaram os neogramáticos, a vogal tônica, tanto latina quanto românica, possui grande estabilidade e dificilmente sofre maiores alterações" (BASSETTO, 2001, p. 48), além disso é, segundo Vasconcelos (19-?, p. 252), "o acento tónico que dá à palavra a sua unidade, sendo como que a sua alma".

Já comentamos que a síncope de consoante sonora intervocálica se mostrou outro importante expediente no processo de economia linguística, conforme atestam o vocábulo latino mediu, que resultou no português "meio" após síncope do $d$, e magis, que resultou em "mais" após síncope da sonora g. No português moderno falado é notável, por exemplo, o que ocorre com a consoante "d - Cai, quase sempre, na sílaba final das formas verbais em ando, endo, indo: andando = andando, veno = vendo, caíno, pôno, e também no advérbio quando, às vezes." (AMARAL, 1955, p. 51), ou seja, o grupo consonantal nd apresenta certa instabilidade em posição intervocálica, tendendo à simplificação em $n$.

Ainda, mais um grupo consonantal localizado na sílaba postônica que tende a sofrer síncope de um de seus elementos quando em posição intervocálica é o grupo $d r$, que perde a vibrante $r$, conforme Bueno (1967, p. 12) "em padre, madre, fradre, resultantes de 
patrem, matrem, fratrem, para muitos houve a síncope: pade, made, frade"; evidentemente, "frade" está grafado segundo a norma culta atual, prenunciando a erosão que "padre" e "madre" tendem a sofrer. Inclusive, indo mais a fundo no modo de falar do povo, lançando mão de um cognato ou congênere desses três vocábulos, "compadre", temos "cumpádi", forma aproximada com a qual muitas vezes se pronuncia ou se escreve o pseudônimo do contemporâneo pagodeiro baiano ("Cumpadi") Compadre Washington - conquanto seja jocosa a alcunha, até pela personagem em questão, é bastante comum na linguagem falada a pronúncia que poderia ser grafada pádi, mádi, cumpádi, cumádi.

Outra tendência que continua atual e que aponta no sentido da economia fonética é a de suprimir sílaba semelhante de palavras diferentes em sequência, como nas frases "O Supremo rasgou a Constituição e, daqui para frente, não poderá..." (Fonte: Blog do Esmael) (para a frente); "Mais de 100 laboratórios de todo mundo lutam contra o tempo para produzir uma vacina contra o novo coronavírus." (Fonte: Istoé Dinheiro) (todo o mundo); "Só 13 dos 513 deputados participaram de todas votações virtuais da Câmara" (Fonte: Brasil 200) (todas as votações); "Revelados primeiros monotrilhos produzidos pela Bombardier para Tailândia" (Fonte: viatrolebus.com.br) (Revelados os primeiros... para a Tailândia); "TSE arquiva ação contra chapa Bolsonaro/Mourão..." (Fonte: Jornal Estado de Minas) (contra a chapa); ou nas expressões voltadas para propaganda "Dia Dia" (Dia a Dia); "Passo ponto" (Passo o ponto); "Fica Dica" (Fica a Dica). Nesses casos divisamos algo entre a "crase", fusão de vogais iguais em juntura - ponto de contato entre duas formas dentro da palavra -, e a "haplologia sintática", omissão de palavra igual ou parecida à outra com a qual está em contato (JOTA, 1976), ambos metaplasmos de supressão; inclusive, Coutinho (1974, p. 148) define a "haplologia" como "síncope especial que consiste na queda de uma sílaba medial, por haver outra idêntica ou quase idêntica na mesma palavra", logo, vemos que não existe uniformidade na literatura especializada.

\section{Considerações finais}

Trabalhar com documentação antiga dá-nos sempre a oportunidade de observar que alguns fenômenos da língua já estavam em variação em séculos anteriores. Por mais formal que seja a escrita de qualquer documento em análise, o escrivão - via de regra - deixa escapar formas que estariam em concorrência, mas que, por algum motivo, não são confirmadas pelos escritores clássicos, tidos como possuidores de bom padrão de língua; apesar de os tempos serem outros, a gramaticografia ser pequena e a imposição de normas ortográficas não ser austera como nos tempos atuais.

Por isso mesmo, podemos observar que muitos fenômenos linguísticos que ocorriam no passado distante continuam a ocorrer no presente, portanto, conhecer mecanismos atuantes que perpassam pela fonética e morfologia de uma perspectiva histórica nos ajuda a compreender a variação linguística no português e a observar que, independentemente da época, o rio continua a correr e a sulcar o gelo. A língua falada sempre sulcará a língua escrita, queiram os puristas ou não. É o correr do rio que não se deixa represar. 
Nesse sentido, espectadores cientes da inexorabilidade desse processo, julgamos ser importante procurar reconhecê-lo e entendê-lo quanto possível, com vistas a registrar e explicar as mudanças que fatores como a síncope operam na superfície da língua bem debaixo dos nossos olhos, flagrando a fugacidade daquilo que costumamos chamar de certo no uso da língua. Os metaplasmos, em especial, a síncope - nas suas variadas manifestações -, são mecanismos reveladores do dinamismo transformador das palavras, contudo, conforme vimos, há certa lógica que possibilita, com alguma margem de segurança, visualizar as tendências linguísticas no âmbito da morfologia (ou mesmo, da sintaxe).

A língua é mais forte do que regras, sempre. Tentar conter essas variações é como "querer tapar o sol com peneira", como diz a expressão popular.

\section{Agradecimentos}

O presente trabalho foi realizado, em parte, com apoio de bolsa de produtividade em pesquisa do CNPq - nível 2 (processo número 308793/2019-6) concedida ao autor Marcelo Módolo.

\section{Referências}

AMARAL, A. O dialeto caipira: gramática - vocabulário. (Obras Completas). Prefácio de Paulo Duarte. São Paulo: Editora Anhembi Limitada, 1955.

ASSIS, M. de. Quincas Borba. (Obras completas, 6). São Paulo: W. M. Jackson Inc., 1957.

BASSETTO, B. F. Elementos de filologia românica: história interna das línguas românicas. v. 2. São Paulo: Editora da Universidade de São Paulo, 2010.

BUENO, S. A formação histórica da língua portuguêsa. 3. ed. rev. São Paulo: Edição Saraiva, 1967.

CÂMARA JR., J. M. Dicionário de filologia e gramática: referente à língua portuguesa. 6. ed. Rio de Janeiro: J. Ozon, 1974.

CARVALHO, A. C. S. de; MÓDOLO, M. Tendências sonoras correntes no latim e no português. Roseta, p. 1-4, 04 set. 2020. Disponível em https://bit.ly/3gwhW2r. Acesso em: 26 nov. 2021. 
CORPUS DO PORTUGUÊS. Disponível em: http://www.corpusdoportugues.org. Acesso em: 26 nov. 2021.

COUTINHO, I. de L. Gramática histórica. 6. ed. rev. Rio de Janeiro: Livraria Acadêmica (Biblioteca Brasileira de Filologia, 4), 1974.

DIAZ Y DIAZ, M. C. Antologia del latin vulgar. Madrid: Editorial Gredos, 1950.

ELIA, S. E. et al. Dicionário gramatical Globo: português, francês, inglês, espanhol, italiano, latino, grego. 2. ed. Rio de Janeiro/Porto Alegre/São Paulo: Editora Globo S. A., 1962.

HOUAISS, A. Dicionário Houaiss da língua portuguesa. Rio de Janeiro: Editora Objetiva Ltda., 2009.

JOTA, Z. dos S. Dicionário de linguística. Rio de Janeiro: Presença (Coleção Linguagem, 2), 1976.

NASCENTES, A. Dicionário etimológico da língua portuguesa. v. 1. Prefácio de W. Meyer Lübk. Rio de Janeiro: Livraria Francisco Alves, 1932.

SILVA NETO, S. da. História do latim vulgar. Apresentação de Rosalvo do Valle. Rio de Janeiro: Ao Livro Técnico S/A, 1977.

TÁVORA, F. O Cabeleira. São Paulo: Editora Três (Coleção Obras Imortais da Nossa Literatura, 16), 1973.

VASCONCELOS, C. M. de. Lições de filologia portuguesa: segundo as preleções feitas aos cursos de 1911/12 e de 1912/13 - seguidas das lições práticas de português arcaico. São Paulo: Livraria Martins Fontes Editora Ltda., 19-?.

VIEIRA, D. Grande diccionário portuguez: ou thesouro da língua portugueza. Porto, Portugal: Ernesto Chardron, Editor. Porto, Portugal: Bartolomeu H. de Moraes, 18711874. 5 vols. 